\title{
Study on the Coating Surface Binder Content by SEM and AFM
}

\author{
Ying $\mathrm{Li}^{1, \mathrm{a}}$, Jie Zhang, Wenjuan $\mathrm{Gu}^{1}$ and Banggui $\mathrm{He}^{1}$ \\ ${ }^{1}$ Faculty of Mechanical and Electrical Engineering, Kunming University of Science and Technology, \\ Kunming, 650093, China \\ ${ }^{a}$ Corresponding author: haishanying@126.com
}

Keywords: Binder distribution; Binder content; Print density; Ink absorption; AFM; SEM

\begin{abstract}
Binder is the essential component of coating color recipe, which has an important influence on the surface topography and properties of coating layer. In this research, the main objective was to investigate into the coating surface binder content related to the coating color recipe. The surface binder content of coating layer was explored in the method of numerical and visual analysis using scanning electrical microscopy (SEM) and atomic force microscopy (AFM). The findings indicated that the binder content in coating color recipe affected the binder distribution of the coating layer surface and amount of binder on coating layer surface decreased with the binder content in coating color recipe increasing. The conclusions were drawn that more amount of binder on the coating surface could contribute to improve the coating surface, which was good to the paper surface characteristics and resulted in low ink absorption and high print density.
\end{abstract}

\section{Introduction}

Factors such as pore structure, coating color formulation, particle arranging and coating speed are important to final printing [1-3]. The amount and type of latex binder has a significant effect on both the structure and chemical-physical properties of coated paper, which affect critical surface properties, e.g., print gloss, roughness, ink setting rate via liquid absorption, and spreading properties [4-7]. It is obvious that what happens in the coating surface of the coated paper is of great important for appearance of final printing. The main objective of this study was to investigate the effect of binder content in coating color recipe on binder distribution of coating layer. To this aim, the coated samples with different amount of binder in color recipes were studied. To observe binder distribution on the coating surface and obtain the relationship between binder content in coating color recipe and binder distribution of coating layer surface was thoroughly analyzed by atomic force microscopy (AFM) and scanning electrical microscopy (SEM). AFM has been used to obtain the three-dimensional characterization of surface topography of paper and the findings provide the basis for the numerical analysis [8].

\section{Experimental}

Preparation of Laboratory Coated Samples. The pigment used for coating was fine Kaolin and Calcium carbonate pigments (supplied by Mao Ming Clay Company, China). The basis weight of the woodfree base paper (supplied by Dong Tang Paper Mill) was $72 \mathrm{~g} / \mathrm{m}^{2}$. The coatings of paper were composed with 50 parts kaolin pigment, 50 parts Calcium carbonate pigment and different parts carboxylic styrene-butadiene latex (supplied by BASF Company, China) with typical types of appropriate additives. The coating formulations were in Table 1. Coating was performed with a bar coater (model K303 Multi-coater, RK Print Coat Instruments Ltd, United Kingdom) with a coating speed of $4 \mathrm{~m} \mathrm{~min}^{-1}$. The coated paper was moved to a drying oven for drying with the drying temperature of $140^{\circ} \mathrm{C}$ for $1 \mathrm{~min}$.

- Coating speed $=4 \mathrm{~m} / \mathrm{min}$

- Drying temperature $=140^{\circ} \mathrm{C}$

- Drying time $=1 \mathrm{~min}$

- Coating thickness $=24 \mu \mathrm{m}$

Preparation of Printing Strips. Ink was offset printing fast-drying cyan ink (TOKA ink, Japan). 
Ink was transferred onto the tissue paper strips using a laboratory printing tester (model IGT Global standard Tester 2, America) and ink distribution apparatus (model IGT Speed Inking Unite 4) with a printing pressure of $500 \mathrm{~N}$ and a printing speed of $0.2 \mathrm{~m} / \mathrm{s}$. The amount of ink transferred onto the ink distributing roller using IGT ink injector was $0.3 \mathrm{ml}$ and the compensation was $0.075 \mathrm{ml}$ every time. The offset printing was carried out under the following conditions.

-Printing speed $=0.2 \mathrm{~m} / \mathrm{min}$

$\bullet$ Printing Pressure $=500 \mathrm{~N}$

-Printing length $=200 \mathrm{~mm}$

- Printing width $=50 \mathrm{~mm}$

OTemperature $=22^{\circ} \mathrm{C}$

$\bullet$ Humidity $=65.5 \%$

Table 1 Coating color recipes

\begin{tabular}{cccccc}
\hline Sample & $\begin{array}{c}\text { Kaolin } \\
\left(\mathrm{pph}^{*}\right)\end{array}$ & $\begin{array}{c}\text { Calcium } \\
\text { carbonate }\left(\mathrm{pph}^{*}\right)\end{array}$ & $\begin{array}{c}\text { SB } \\
\left(\mathrm{pph}^{*}\right)\end{array}$ & $\begin{array}{c}\text { Solids } \\
(\%)\end{array}$ & $\begin{array}{c}\text { Coating } \\
\text { thickness }(\mu \mathrm{m})\end{array}$ \\
\hline A & 50 & 50 & 20 & 60 & 24 \\
B & 50 & 50 & 15 & 60 & 24 \\
C & 50 & 50 & 10 & 60 & 24 \\
\hline
\end{tabular}

* Parts per hundred

Measurements of Scanning Electron Microscopy. Scanning electron microscopy (Hitachi S3700N, Japan) was utilized to investigate the elemental composition of the coatings surface. For SEM observation, all coating samples were gold coated and 20KV beam energy was used to get the information of elemental composition of the coatings.

Atomic Force Microscopy. In order to characterize the coating surface binder content, the atomic force microscopy (AFM) used was a commercial Nanoscope IIIa from Digital Instruments (Santa Barbara, CA). The images of surface topography were captured with tapping mode in air using standard Si3N4cantilevers. A $10 \mu \mathrm{m} \times 10 \mu \mathrm{m}$ scanning area was chosen to describe the surface microstructure of paper [9]. Adhesion images were captured simultaneously. The AFM maps must be treated with flattening order before measurements. Surface plot, depth, roughness and section measurements were carried out using the Nanoscope IIIa image analysis software.

\section{Results and Discussion}

Study on the Binder Content of Coating Surface by SEM. Scanning electrical microscopy (SEM) was used to investigate the surface elemental composition of the coating samples. The surface composition in atomic percentage was calculated, and then was presented as energy spectrum. Results are shown in Tables 2. The Al, Si and part of the $\mathrm{O}$ signals come from the clay. The main part of the $C$ signal originates from the SB latex. The amount of carbon originating from each one was calculated with the help of SEM software (Table 2). Table 2 shows the variation of surface composition with different drying method as found from SEM. In all coating samples investigated, the overall binder content is not same, i.e. binder content of coating surface differentiate with different binder content. It can be concluded from Table 2 that highest binder content in coating color recipe results in the highest amount of carbon content on the coating surface and lowest binder content in coating color recipe results in the lowest amount of carbon content on the coating surface.

Table 2 SEM surface elemental composition in at.\% of coating surface

\begin{tabular}{cccc}
\hline & $\mathrm{A}$ & $\mathrm{B}$ & $\mathrm{C}$ \\
\hline $\mathrm{C}$ & 7.55 & 6.38 & 5.76 \\
$\mathrm{O}$ & 71.43 & 70.15 & 70.32 \\
$\mathrm{Si}$ & 9.59 & 11.28 & 11.45 \\
$\mathrm{Al}$ & 11.22 & 11.94 & 12.21 \\
$\mathrm{~K}$ & 0.21 & 0.25 & 0.26 \\
\hline
\end{tabular}


Visualization of Binder Content on Coating Surface from Adhesion Maps. AFM adhesion maps mainly capture variation in materials compliance. Typical adhesion maps of coating surface with different color recipes were shown in Fig. 1. AFM adhesion maps were used to locate and quantify the binder coverage on the pigment coating surface in this research. Visualization of the adhesion maps suggested that there was a correlation between pigment arrangement and local binder distribution. It was obtained that the binder film surrounded the pigment particles by filling the interstices between them. Because the coating color recipe was known, it was possible to discriminate pigments and binder from the adhesion maps. Differences in the binder surface coverage for samples were somewhat logical, since the highest and lowest surface coverage was observed for coating sample A and C, respectively. For observed coating samples, binder amount decreased in the surface covering area with the binder content decreasing in the color recipes, as illustrated in Table 2. For A with high binder content, binder gave a considerably higher surface covering area than B and C. The structure of the coating sample C with low binder content seemed to display the smallest binder microscopic scopes. On the contrary, sample A with high binder content seem to take on the largest scopes where the binder accumulates.

(A)

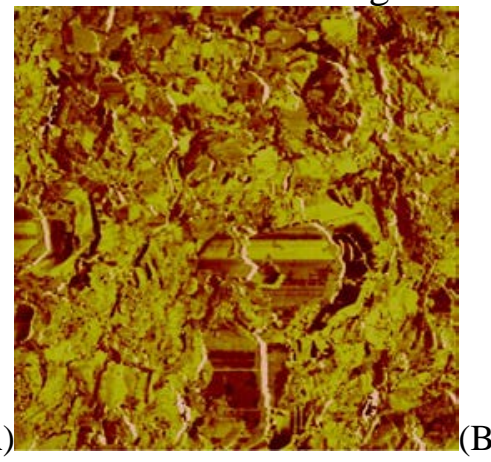

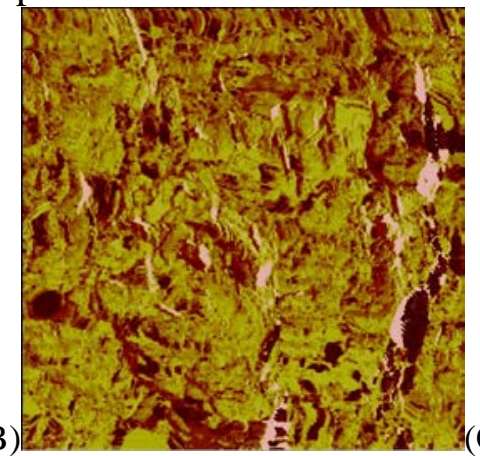

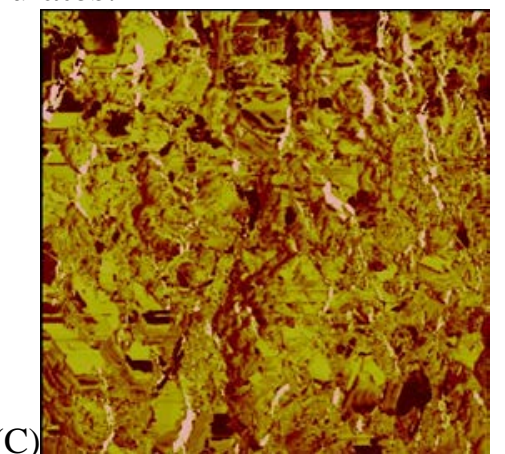

Fig.1. AFM adhesion maps of $10 \mu \mathrm{m} \times 10 \mu \mathrm{m}$ areas of coated paper. Binder is shown as dark. The amount of binder on the coating surface increases with increasing binder content.

Effect of Surface Binder content on Ink absorption. Changes in ink absorption and print density with the different binder content in coating color recipe were shown in Fig. 2. The results obtained were explored as the basis for discussion about the effect of binder content on printing quality. Sample A had the highest print density and the lowest ink absorption. In contrast, Sample C had the lowest print density and the highest ink absorption. It suggested that ink absorption increased and print density decreased with the adding of binder content. Though more binder resulted in lower ink absorption shown in Fig.2, more binder content coating caused higher print density. This phenomenon indicated that the most of ink of sample A set on the coating surface and did not penetrate into the coating interior. The more amount of ink penetrated into paper coating and fewer amount of ink set on the surface of paper, which resulted in that higher amount of ink usage produced lower print density.

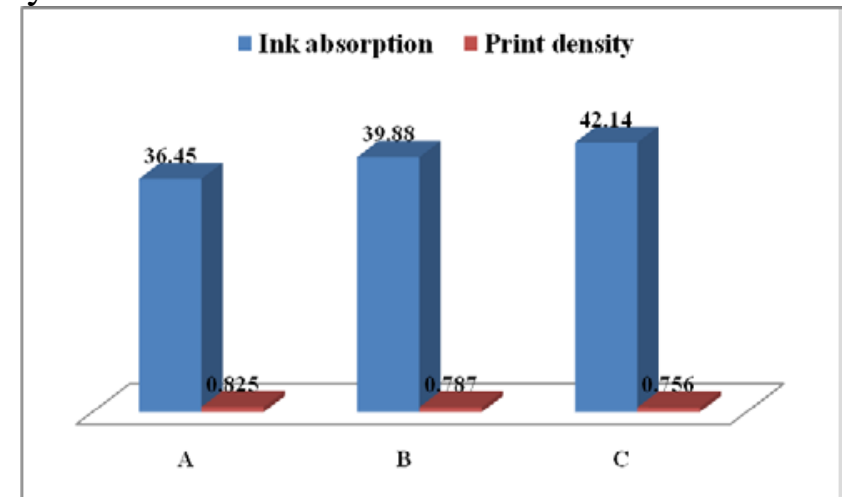

Fig.2. Print density and ink absorption of samples which include the different parts binder (A:20 parts binder, B:15 parts binder, C:10 parts binder) 


\section{Conclusions}

Investigation into the relationship between surface binder distribution and binder content in coating color recipe can be obtained. The conclusions were drawn that binder content in coating color recipe affect the surface binder content of coating layer owing to the different binder accumulating condition on the coating surface. More amount of binder in the coating was good to improve the paper properties, which resulted in low ink absorption and high print density. The more amount of binder in the consolidation phase of coating color made a contribution to the forming of the coating layer, which made the coating surface good to printing performance. It could be concluded that it was useful method to utilize SEM and AFM to characterize the binder distribution in coating surface. Binder was critical to the surface topography and structure and characteristics, which played a major role in determining print gloss, print density and appearance of final printing.

\section{Acknowledgements}

The authors express their gratitude to the Yunnan Province Science and Technology Department (Project KKSY 2012/01059 and KKSY 2012/01051) for financial support.

\section{References}

[1] D.W. Donigian, J.N. Ishley, K.J. Wise: TAPPI J. 80 (5) (1997), p.145.

[2] T.P. Glatter, D.W. Bousfield: TAPPI J. 80 (7) (1997), p.125.

[3] D. M. Desjumaux, D.W. Bousfield: Progress in Organic Coatings. 38(2) (2000), p.89.

[4] M.T. Prykäri, E. Alarousu, H. Koivula, M. Myllys, A. Lähteelä, M. Toivakka, J. Timonen, R. Myllyl”a and K.-E. Peiponen: Colloids Surf., A299 (2007)p.101.

[5] P. Heikkil€a and N. Milosavljevic: Drying Technology 20 (1) (2002), p.211.

[6] S. Rousu, P.A.C. Gane, D. Speilmann: Nordic Pulp Paper Res. J. 15 (5) (2001), p.527.

[7] J.S. Preston, N.J. Elton, A. Legrix, C. Nutbeem: Proceeding of TAPPI Advanced Coating Fundamentals Symposium, San Diego, May 2001.

[8] G. Udupa, M. Singaperumal, R.S. Sirohi, M.P. Kothiyal, Meas. Sci. Technol. 11 (2000), p.315.

[9] C. M. Tåg, M. Juuti, K. E. Peiponen, J.B. Rosenholm, Colloids Surf. A 317 (2008), p.658. 